\title{
Correction to: Comparison between the musician-specific seating position of high string bow players and their habitual seating position - a video raster stereographic study of the dorsal upper body posture
}

Daniela Ohlendorf ${ }^{1 *}$, Jennifer Marx¹, Kathrin Clasen², Eileen M. Wanke ${ }^{1}$, Stefan Kopp ${ }^{2}$, David A. Groneberg ${ }^{1}$ and Stefanie Uibel ${ }^{1}$

Correction to: Journal of Occupational Medicine and Toxicology (2018) 13:34.

https://doi.org/10.1186/s12995-018-0217-6

After publication of the original article, the authors reported an error which needed to be corrected:

In the methodology section of the article [1], Fig. 1 and Fig. 2 have been mistakenly published. They exemplify the methodology of the back scan. The correct two figures are listed below. The legends remain the same.

\section{Author details}

${ }^{1}$ Institute of Occupational, Social and Environmental Medicine, Goethe-University

Frankfurt/Main, Theodor-Stern-Kai 7, 60590 Frankfurt/Main, Germany. ${ }^{2}$ School of dentistry, Department of Orthodontics, Goethe University Frankfurt/Main,

Theodor-Stern-Kai 7, 60590 Frankfurt am Main, Germany.

Received: 8 March 2019 Accepted: 8 March 2019

Published online: 13 March 2019

\section{Reference}

1. Ohlendorf $D$, et al. Comparison between the musician-specific seating

position of high string bow players and their habitual seating position - a video raster stereographic study of the dorsal upper body posture. Journal

of Occupational Medicine and Toxicology. 2018;13:34. https://doi.org/10.

1186/s12995-018-0217-6.

\footnotetext{
* Correspondence: ohlendorf@med.uni-frankfurt.de

${ }^{1}$ Institute of Occupational, Social and Environmental Medicine, Goethe-University

Frankfurt/Main, Theodor-Stern-Kai 7, 60590 Frankfurt/Main, Germany
}

(c) The Author(s). 2019 Open Access This article is distributed under the terms of the Creative Commons Attribution 4.0 International License (http://creativecommons.org/licenses/by/4.0/), which permits unrestricted use, distribution, and reproduction in any medium, provided you give appropriate credit to the original author(s) and the source, provide a link to the Creative Commons license, and indicate if changes were made. The Creative Commons Public Domain Dedication waiver (http://creativecommons.org/publicdomain/zero/1.0/) applies to the data made available in this article, unless otherwise stated. 


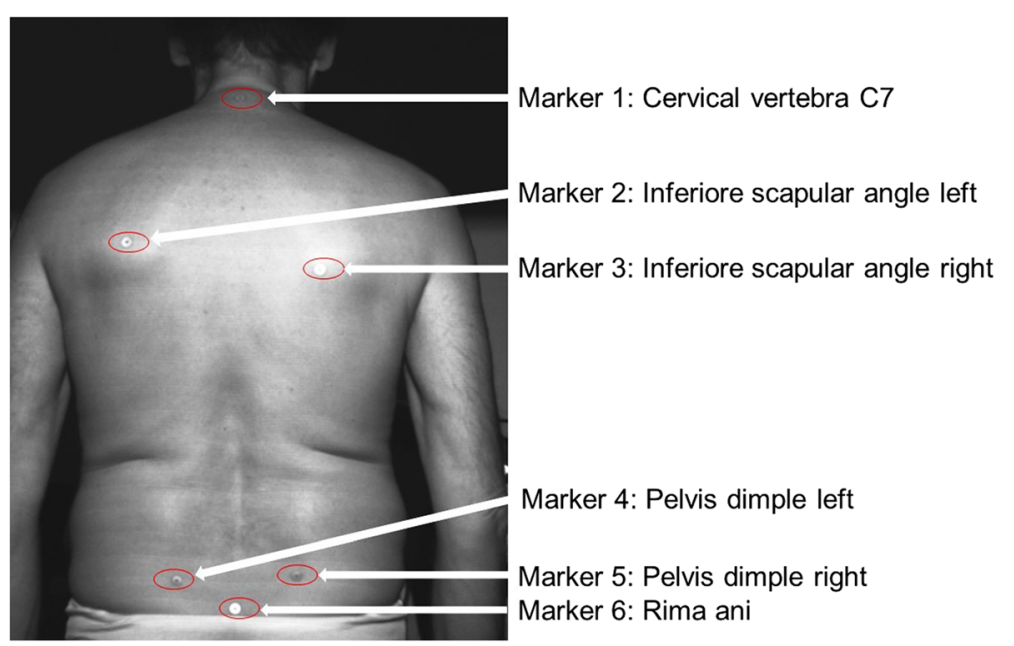

Fig. 1 Location of the 6 marker

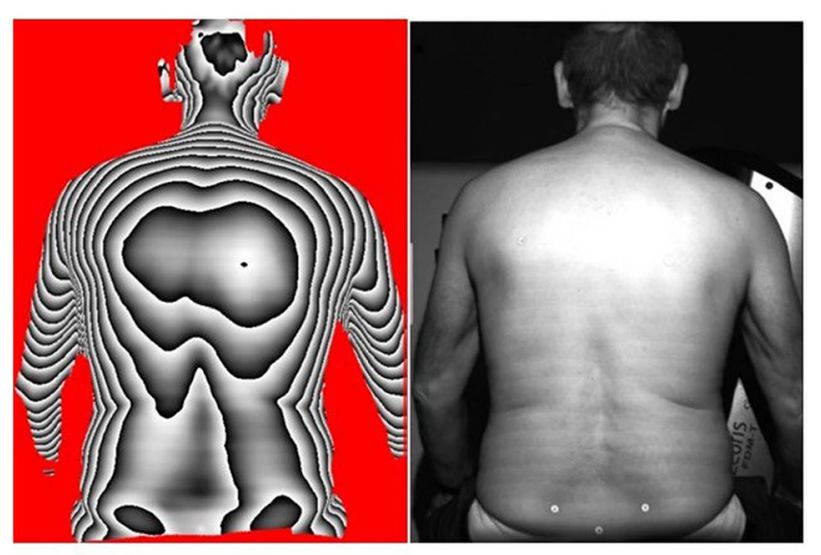

Position 1

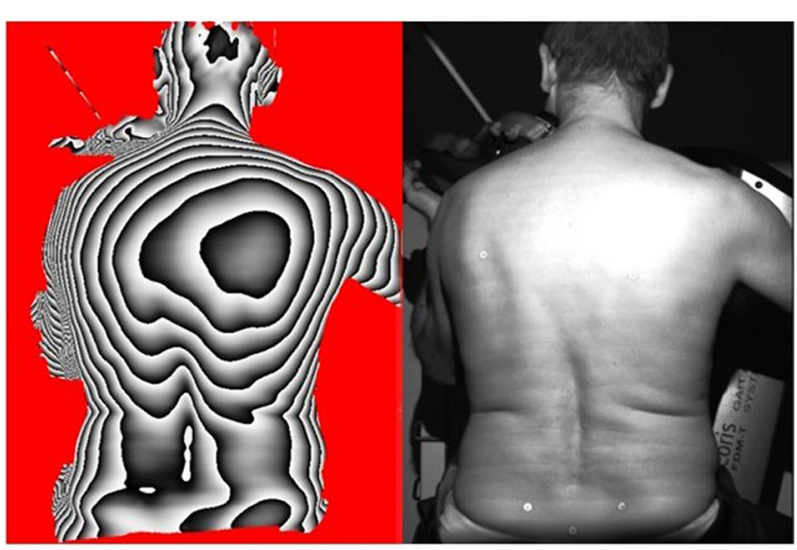

Position 2

Fig. 2 Group 1: Showing comparative positions 1 / 2 